\title{
COMPUTATIONAL STUDY OF THE TIME-DEPENDENT FLOW FIELD OF A WATER-MOLASSES MIXTURE INSIDE A STIRRED VESSEL
}

\author{
Suci Madhania ${ }^{1,2}$, Tantular Nurtono ${ }^{2}$, Sugeng Winardi ${ }^{2}$, Yuswan Muharam ${ }^{1}$, Widodo Wahyu \\ Purwanto $^{1 *}$ \\ ${ }^{1}$ Department of Chemical Engineering, Faculty of Engineering, Universitas Indonesia, Kampus UI \\ Depok, Depok 16424, Indonesia \\ ${ }^{2}$ Chemical Engineering Department, Institut Teknologi Sepuluh Nopember, Kampus ITS Sukolilo, \\ Surabaya 60111, Indonesia
}

(Received: July 2018 / Revised: October 2018 / Accepted: April 2019)

\begin{abstract}
Detailed information on the flow field in the operation of a mixing unit is necessary for the optimal design of the reactor. The flow field characteristic is an essential factor in obtaining an optimal stirred vessel design. The efficiency of the stirred vessel system depends on, for example, the stirred vessel geometry, the flow induced by the impeller, the working fluid properties and the operating condition. The aim of this study is to exhibit the time-dependent flow field of the mixing process inside a stirred vessel for different propeller rotational speeds using computational fluid dynamics methods. The working fluid in question is molasses and water, which is a miscible liquid. The stirred vessel is a conical-bottomed cylindrical vessel $(D=0.28 \mathrm{~m}$ and $H=0.395 \mathrm{~m})$ equipped with a three-blade propeller $(d=0.036 \mathrm{~m})$. The transient calculation was conducted using ANSYS Fluent version 18.2. The Mixture multiphase flow model coupled with the Reynolds-averaged Navier-Stokes Standard $k-\varepsilon$ (SKE) turbulence model was applied to capture the information on the time-dependent flow fields at various propeller rotational speeds inside the stirred vessel. The flow generated by the propeller was compared at $1000 \mathrm{rpm}, 1300$ rpm and $1500 \mathrm{rpm}$. The Multiple Reference Frame method was used to solve the moving domain and stationary domain multiple frames case. The results revealed the local velocity, flow pattern, molasses volume fraction value, density gradient distribution, power number and flow number. The profile of all the variables determines the optimal operating conditions for the degree of mixing required.
\end{abstract}

Keywords: Computational fluid dynamics; Multiphase flow; Propeller; Stirred vessel; Turbulent flow

\section{INTRODUCTION}

The blending of water and molasses with different properties has related applications in the production of bioethanol. The water-molasses mixture includes the miscible liquid system. Homogenization of two mutually dissolvable liquids is achieved through molecular diffusion and convection, but stirring can speed up the homogeneous condition reaches. The stirred vessel is one type of mixing equipment used in an industrial process. The flow field information inside the stirred vessel is necessary for the optimal design of the reactor. The efficiency of the stirred vessel system depends on, for example, the stirred vessel geometry and the flow induced by the impeller.

\footnotetext{
*Corresponding author's email: widodo@che.ui.ac.id, Tel. +62-21-7863516, Fax. +62-21-7863515 Permalink/DOI: https://doi.org/10.14716/ijtech.v10i3.2926
} 
The flow generated by the impeller is influenced by various factors including the shapes and number of impeller (Muharam \& Kurniawan, 2016), the impeller size, the impeller type (Zhao et al., 2011; Sossa-Echeverria \& Taghipour, 2015), the location and layout of the impeller (Rahimi, 2005) and rotational speed.

The experimental study is the primary method used to describe the flow characteristic in a stirred vessel. Direct measuring techniques can disturb the flow field, while indirect methods may not be appropriate as they are often too expensive and take a long time to carry out. However, advancements in computer technology and mathematical modeling leads researchers to prefer to use computational fluid dynamics (CFD) over an experimental study. CFD has become a capable device for describing fluid flow and has also been successfully used to predict the mixing behavior of the miscible liquid system, e.g. in the mixing of ethanol and glycerol (Al-Qaessi \& Abu-Farah, 2014), the homogenisation of two mutually dissolvable fluids with different properties (Derksen, 2011), the water-ethanol system (Orsi et al., 2013) and the blending of two miscible liquids with different densities and viscosities (Montante et al., 2016).

The flow conditions in stirred tanks are mostly turbulent due to the presence of the impeller; therefore, the selection of the turbulence model should be appropriately considered as a way of resolving the effect of turbulence inside the system unit that operates at a high Reynolds number flow (Daryus et al., 2016). Commonly encountered forms of turbulence model include the Direct Numerical Simulation (DNS), Large Eddy Simulation (LES) and Reynolds-Averaged NavierStokes (RANS) models. Time-resolved and full-length-scale Navier-Stokes equations without any models or assumptions are solved directly by DNS. In LES, large eddies are resolved directly, while the effects of small eddies are modeled using subgrid-scale stress. However, the equations in RANS calculate the average of large eddies and some assumptions should be applied. Meanwhile, in real conditions, the tremendous computational costs of the LES and DNS still pose a significant barrier and there is a greater focus on mean flow characteristics as opposed to detailed turbulence. Therefore, the RANS model is commonly used. The RANS model comprises the standard k- $\varepsilon$ (SKE) model (Launder \& Spalding, 1974), the renormalization k- $\varepsilon$ (RNG) model (Yakhot \& Orszag, 1986) and the realizable k- $\varepsilon$ (RKE) model (Shih et al., 1995).

In CFD, a stirred tank system is included in the multi-reference frame category due to the presence of the impeller, which is a moving part. There are several approaches to handling multi-reference frame cases, among others the Sliding-Mesh (SM) and the Multiple Reference Frame (MRF) method. The SM is an unsteady approach to treat the moving and stationary frame interaction, while MRF is a steady state condition (Luo et al., 1994).

Power number $\left(N_{P}\right)$ and Flow number $\left(N_{Q}\right)$ are important factors for characterising the impeller inside the stirred vessel. Zadghaffari et al. (2009) used the power number in his studies on mechanical agitation inside the stirred vessel. The power number can be obtained using both the torque applied in the impeller and by integrating the turbulence energy dissipation rate over the tank volume (Ge et al., 2014). However, based on Singh et al. (2011), torque-based prediction is more accurate than prediction based on the turbulence energy dissipation rate.

Up to now, the main progress of CFD study on the mixing process inside a stirred vessel has been achieved in the context of a top-entry installed propeller configuration. However, relatively few studies have been undertaken with regard to a side-entry configuration, e.g. CFD simulation on the mixing of crude oil in flat-bottomed cylindrical storage tanks (Dakhel \& Rahimi, 2004), the influence of propeller layout on the mixing of the crude oil system inside a stirred tank (Rahimi, 2005), the intensity of solid-liquid mixing inside a stirred tank with various impeller layouts ( $\mathrm{Wu}$, 2011), and the mixing of pseudoplastic solutions (Sossa-Echeverria \& Taghipour, 2015). 
This study aims to present detailed information on the time-dependent flow fields generated by a three-blade propeller at three different rotational speeds for the water-molasses mixing process in a side-entry configuration stirred tank using the ANSYS Fluent CFD method. This research is a continuation of previous research that has reviewed the mixing effectiveness of different propeller installments (Madhania et al., 2017) and the mixing phenomena associated with different computational solution strategies (Madhania et al., 2018).

\section{METHODS}

Transient CFD simulations were performed using ANSYS Fluent 18.2 in a Hewlett-Packard Z640 workstation

\subsection{Model Description}

The fluid system used in this study comprises water and molasses, which have different properties in terms of their mutual solubility; hence, the system includes a multiphase flow category. The Mixture multiphase model was applied to solve the continuity and momentum equations. The mixture had a greater composition of water than molasses. Therefore, water is treated as the continuous phase and molasses is the dispersed phase. In this study, the RANS Standard $k-\varepsilon$ (SKE) turbulence model was chosen. The interaction of the flow between the moving frame and the stationary frame was solved using the MRF method.

The Power Number $\left(N_{P}\right)$ and Flow Number $\left(N_{Q}\right)$ can be determined in the following equation (Marshall \& Bakker, 2004).

$$
N_{P}=\frac{P}{\rho N^{3} d^{5}}
$$

In this expression, $\rho$ is the density of the working fluid, $N$ is the propeller rotational speed, $d$ is the propeller diameter and $P$ is the power delivered to the fluid, as follows:

$$
P=2 \pi N \tau
$$

In Equation 2, $\tau$ is the torque which is obtained by integration of the pressure on the impeller blade. By calculating the power consumption, the power number can subsequently be obtained.

Flow number is a measure of the pumping capacity of an impeller and is defined as:

$$
N_{Q}=\frac{Q}{N d^{3}}
$$

where $Q$ is the flow rate produced by the impeller, which is determined by integrating the total outflow through the discharge region.

\subsection{Geometric System}

The geometric system is shown in Figure 1. The propeller is installed on the conical side at an angle of $45^{\circ}$. The grid generation of the system can be seen in Figure 1c, while the mesh detail information is presented in Table 1.

Table 1 Mesh detail information

\begin{tabular}{lccc}
\hline & Moving Domain & Stationary Domain & Total \\
\hline Elements & 888,293 & 206,850 & $1,095,143$ \\
Nodes & 217,016 & 45,110 & 262,126 \\
Average Skewness & 0.218 & 0.233 & \\
Maximal Skewness & 0.785 & 0.831 & \\
\hline
\end{tabular}


The number of cells used in this study has passed that of the grid independence test stage. The grid independence test was started by making five different mesh sizes. Each mesh was then simulated by applying the same solution strategy in transient mode and using water as the working fluid. The solution result parameters $(f)$ of each mesh were then compared. The local velocity data in the $x$-direction or $u$-velocity at the observation points were used as a parameter. The coordinates of the observation point were set at $x=0.05 ; y=0.02 ; z=0$. Based on the five mesh sizes, only three types had a similar trend in terms of their local $u$-velocity changes over 10 s. The parameter $(f)$ of the three meshes was then inputted into the calculation using the Grid Convergence Index (GCI) method (Roache, 1994; Roache, 1997), which is based on a grid refinement error estimator according to the generalized Richardson Extrapolation theory. Based on the GCI calculations, for the safety factor $(F s)$ of 1.25 , a number of cells equal to $1,095,143$ obtained the target value of 0.05 or equivalent to 0.95 ; as a result, this mesh size was declared independent and can be used to solve the fluid flow problem of mixing water and molasses in a stirred tank.

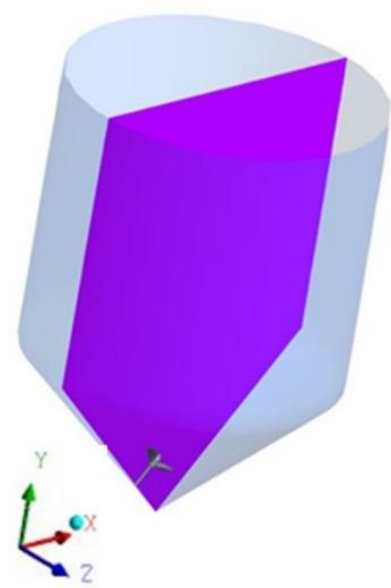

(a)

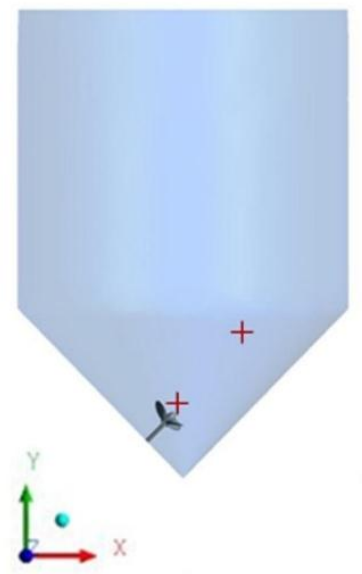

(b)

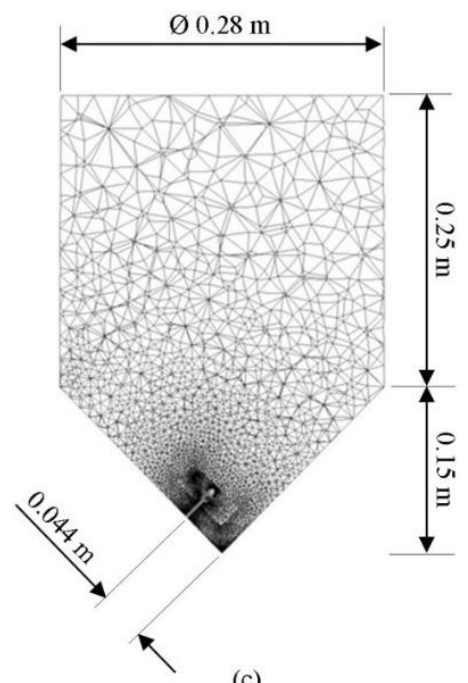

(c)

Figure 1 The observation plane (a), the observation point (b) and the grid generation of the system (c)

\subsection{Initial Condition}

The molasses viscosity is 2.09 Pa.s, while that of water is 0.001003 Pa.s. The initial volume fraction of water/molasses is defined relative to their respective heights in the vessel. The height of the molasses inside the vessel was set at $0.158 \mathrm{~m}$, and the height of the water that filled the vessel was set at $0.235 \mathrm{~m}$ above the molasses (Madhania et al., 2018).

\subsection{Boundary Condition}

The contact region between a moving-stationary frame is defined as the interface boundary condition. The shaft is treated as an absolute moving wall. The propeller is treated as a moving wall which is relative to the moving frame as an adjacent cell zone, and the rotational speed was set at 1000, 1300 and $1500 \mathrm{rpm}$. At the liquid surface, the axial gradient of the dependent variables is set to zero and then set as a symmetry boundary condition. The bottom and cylindrical walls are derived assuming the no-slip condition and treated as stationary walls. No-slip means that the velocity of the fluid at the wall boundary is set to zero.

\subsection{Solution Setup}

The operating conditions were defined by turning on gravity at the $y$-axis $=-9.81 \mathrm{~m} / \mathrm{s}^{2}$ and setting the unit of the angular speed to rpm. The Semi-Implicit Method for Pressure-Linked Equations (SIMPLE) was used to solve the continuity and momentum equations, especially for their coupling (Van Doormaal \& Raithby, 1984). The spatial discretization was set to first-order 
upwind for the momentum, volume fraction, turbulent kinetic energy and turbulent dissipation rate equations (Ansys-Fluent, 2017). The Pressure Staggering Option (PRESTO) was used for the spatial discretization of pressure (Patankar, 1980). The convergence criterion was set to $1 \times 10^{-}$ ${ }^{5}$ for velocities and $1 \times 10^{-4}$ for volume fraction. The first-order Implicit scheme was used for the time step for the turbulence model. The time step was set to $0.01 \mathrm{~s}$.

\section{RESULTS AND DISCUSSION}

The time-dependent flow field of the mixing of molasses and water was analyzed through an observation plane and observation point, as shown in Figure 1. The positions of observation points 1 and 2 were $x=-0.005 ; y=-0.08 ; z=0$ and $x=0.05 ; y=-0.02 ; z=0$, respectively.

\subsection{Comparison of Flow Pattern and Flow Velocity}

The velocity vector of the flow that represents the flow pattern inside the stirred vessel at 1000, 1300 and $1500 \mathrm{rpm}$ located on an observation plane is shown in Figure 2a. Based on this, a similar phenomenon occurs at each propeller rotational speed; it can be seen that the three-blade propeller delivers an axial flow direction. Fluid that is sucked and then flows in the negative axial direction first enters the propeller then exits the back of the propeller before hitting the bottom wall and changing direction to form a double circulation around the propeller. The fact that a similar phenomenon is also found at different rotational speeds indicates that the flow pattern formed does not depend on the rotational speed of the propeller.

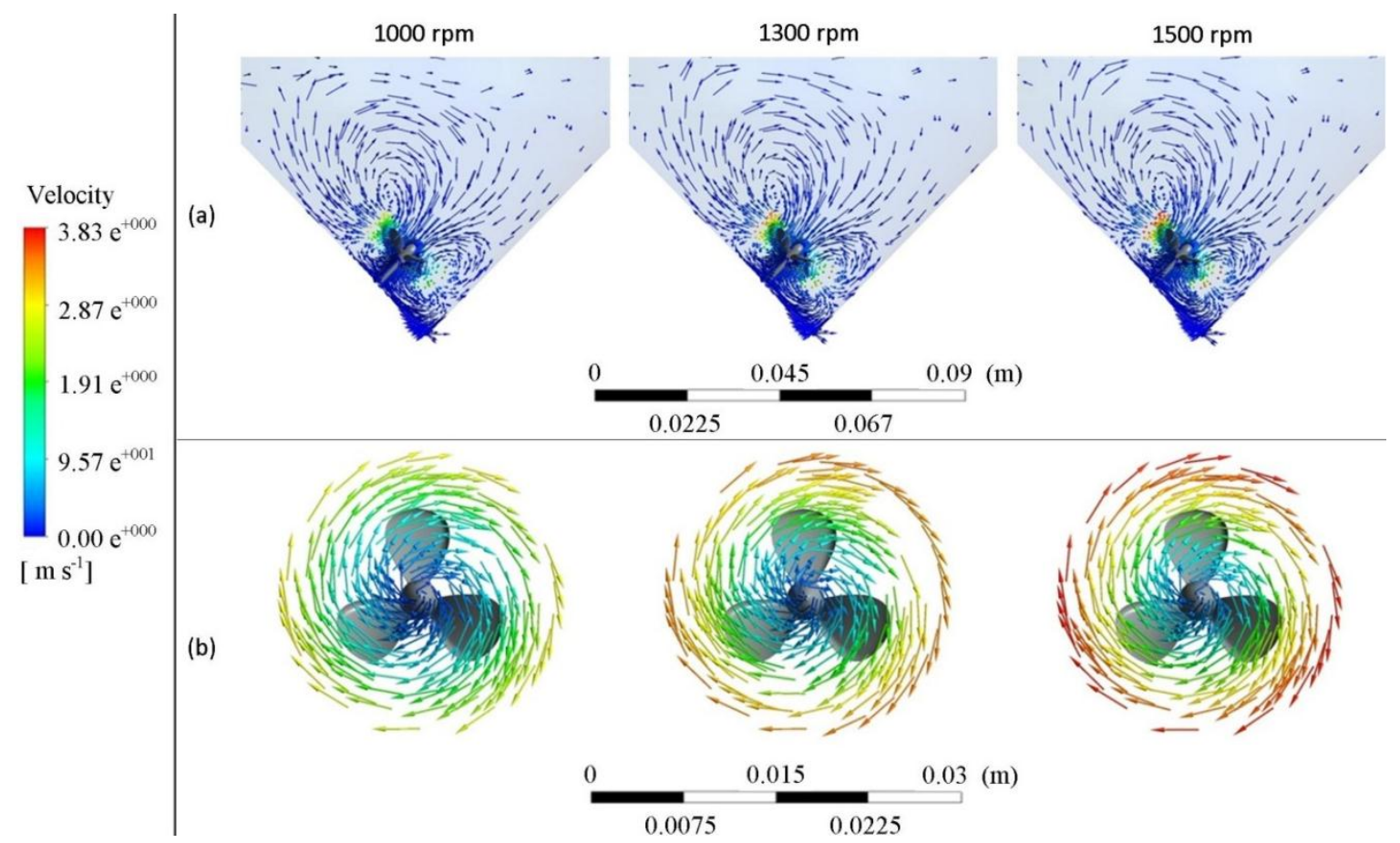

Figure 2 The velocity vector analysis of the observation plane (a) and the flow velocity on the propeller discharge region (b) at different propeller rotational speeds

The flows generated by the propeller in the discharge region for every propeller rotational speed are displayed in Figure $2 b$. Based on the images, the vector has a clockwise direction. The vectors generated from various propeller rotational speeds are shown in different colors, indicating that the value of the flow velocity increases as the propeller rotational speed increases. The highest velocity is shown in red, while the propeller vicinity velocity shows a maximum velocity value of $3.83 \mathrm{~ms}^{-1}$. 


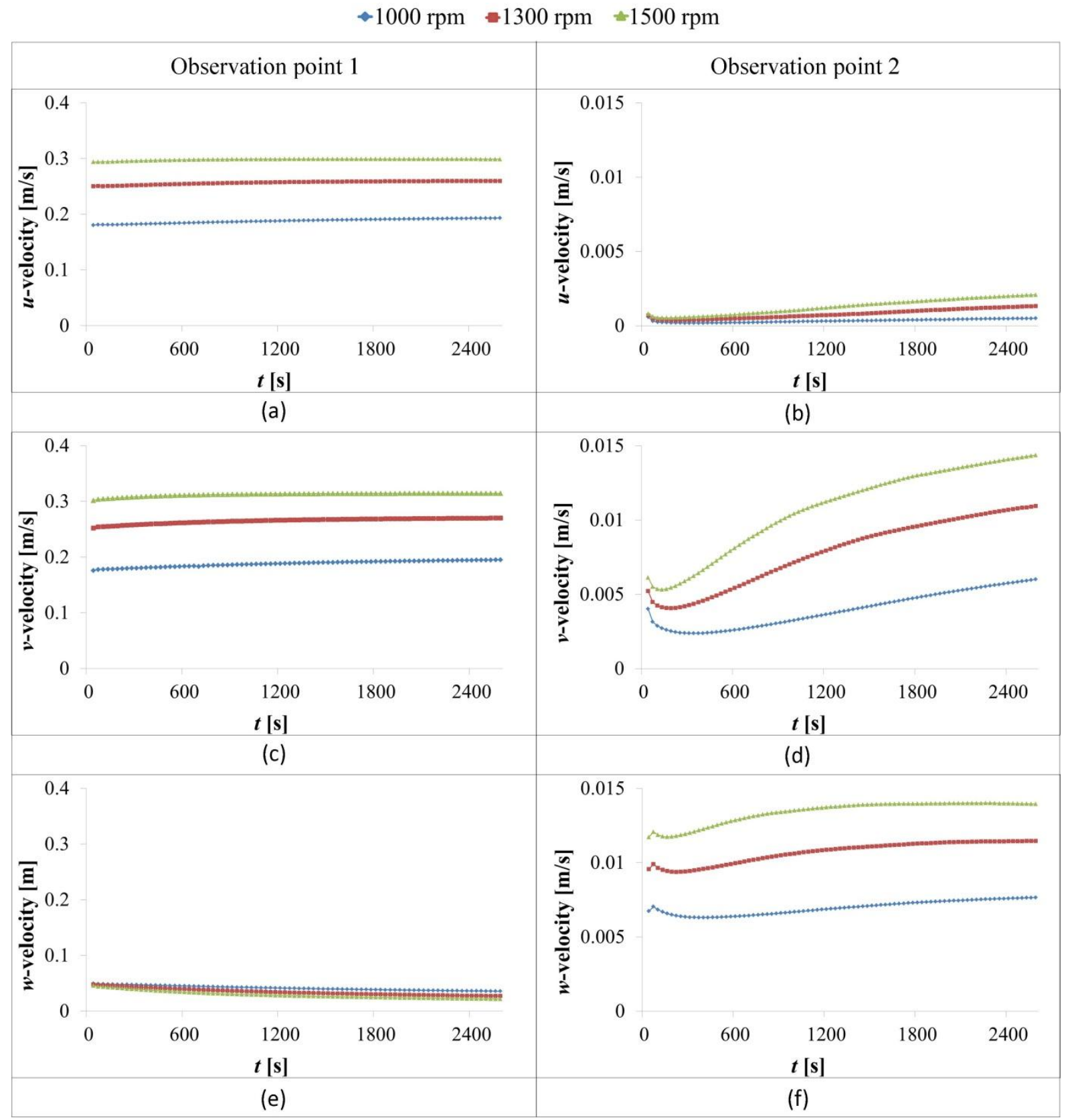

Figure 3 The local velocities of $x, y$ and $z$-direction at observation point 1 and point 2

The predicted local velocities of the flow produced by the three-blade propeller at three different rotational speeds inside the stirred vessel are presented in Figure 3. The plot of the local $u$-velocity and $v$-velocity at observation point 1 , Figures $3 \mathrm{a}-3 \mathrm{c}$, and observation point 2 , Figures $3 \mathrm{~b}-3 \mathrm{~d}$, generally show similar patterns. However, some slight differences can also be noted. Observation point 1 shows a flat trend as a function of time while observation point 2 shows increases in velocity as time increases. This indicates that the $u$-velocity and $v$-velocity near the propeller are similar at any time, while at point 2 it is a function of time, thus revealing that the fluid movement at point 2 depends on changes in the intensity of the local turbulence. A similar trend is also shown for the $w$-velocity profile at observation point 2 (see Figure $3 \mathrm{f}$ ), despite the fact that Figure $3 e$ shows a decrease in velocity with increasing rotational speed. This phenomenon occurs due to the propeller being an axial flow impeller type; thus, the fluid movement near the propeller is dominant in the $x$ - and $y$-direction. Therefore, the longer the stirring time, the velocity in the $z$ - 
direction or $w$-velocity near the propeller decreases as the propeller able to transfers the energy across a wider mixing area.

\subsection{Molasses Distribution}

The distribution of molasses inside the stirred vessel was reviewed based on an analysis of the prediction of the density gradient, molasses volume fraction and density contour. The density gradient and molasses volume fraction at the observation point for the different stirring rates are reported in Figure 4, while a comparison of the density contours at different propeller rotational speeds can be observed in Figure 5.

Figure 4a shows changes in the local density gradients as a function of time during the agitation process at the three variations of propeller rotational speed. The value of the density gradient shows the differences in density between the two fluids at the observation point. In the initial condition, the value of the density gradient is 0 because there are pure molasses at the observation point. There was an increase in density gradient once the stirring began, indicating that water is starting to be sucked into the molasses area. This means that the density gradient value can also indicate the presence of water inside the molasses area. The density gradient increases with the stirring time until the latter reaches around $200 \mathrm{~s}$, at which point there is a rapid decline in the gradient value until $600 \mathrm{~s}$; after that, the decrease becomes more gradual. This phenomenon occurs because the molasses and water are mutually dissolved. Density gradient changes can thus be used to determine the time at which mixing is achieved; a homogeneous condition thus occurs when the value of the density gradient is 0 .

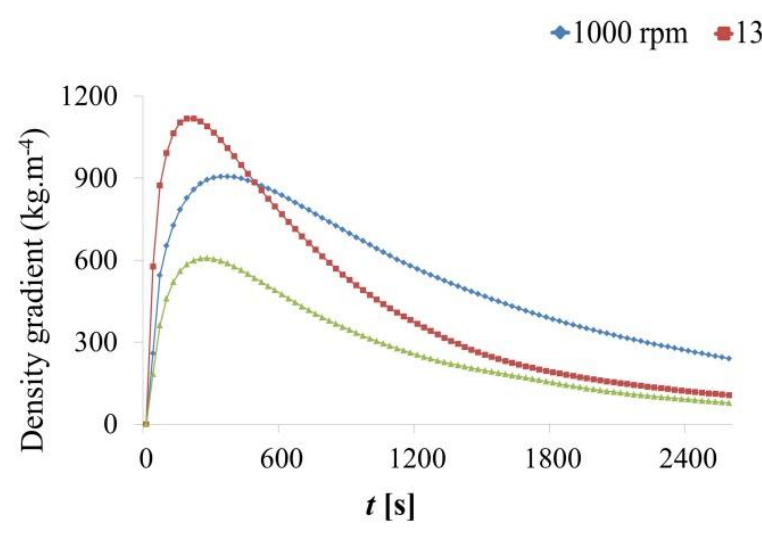

(a)

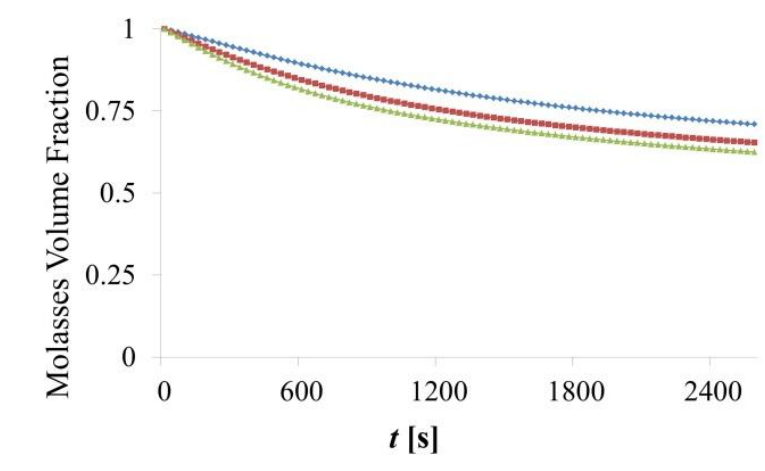

(b)

Figure 4 The density gradient (a) and molasses volume fraction (b) at various propeller rotational speeds

As seen in Figure 4b, the prediction of the molasses distribution fraction value decreases slightly as a function of time under the mixing process, and it decreases as the rotational speed increases. These phenomena indicate that there is a property change in the working fluid due to the watermolasses mixing process.

Based on Figure 5, the observation conducted through the density contour reveals that the mixing of water and molasses began when the molasses located in front of the propeller were sucked in due to the propeller's rotation. During the mixing process runs, based on the flow pattern information that has been discussed previously, the circulation loop becomes wider until it reaches the water-molasses boundary region and sucks water into the molasses region, with both liquids then being mutually dissolved. When the water is sucked into the molasses region, the mixing process begins; this produces a change in the working fluid properties at the bottom of the tank. The property changes observed are density changes in the observation plane. This phenomenon leads to fluid density changes until it reaches the homogeneous condition. This 
density change occurs slowly because the viscosity of molasses is very high, which means that a longer time is required for the transfer of energy from the stirrer to the working fluid to reach across a wider area.

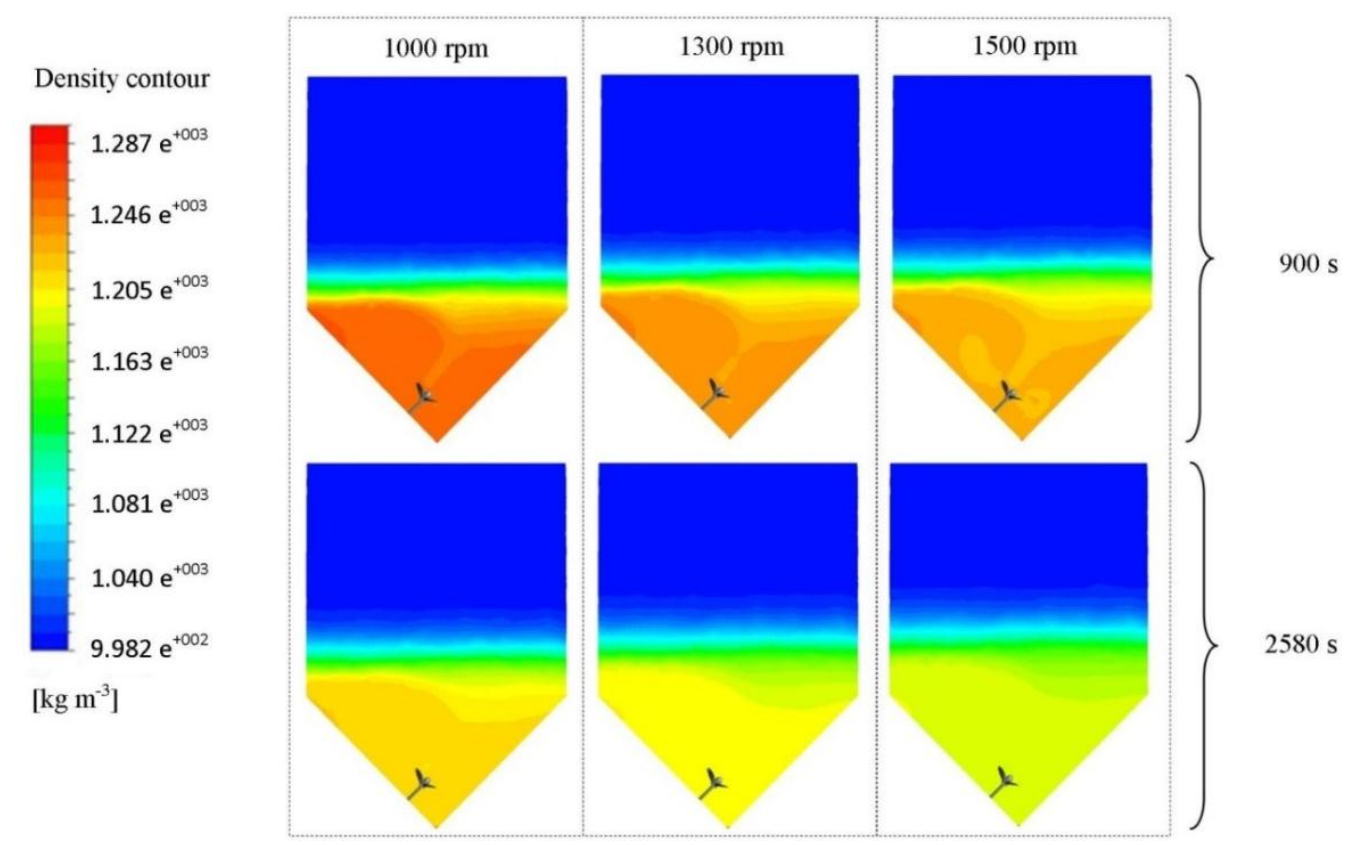

Figure 5 The density contour of the flow generated by the propeller at different rotational speeds

\subsection{Impeller Characteristics}

The impeller characteristics are reviewed based on an analysis of the power number and flow number, which will be illustrated in the subsequent sections. The predicted power numbers of the three different propeller rotational speeds are shown in Figure $6 a$.

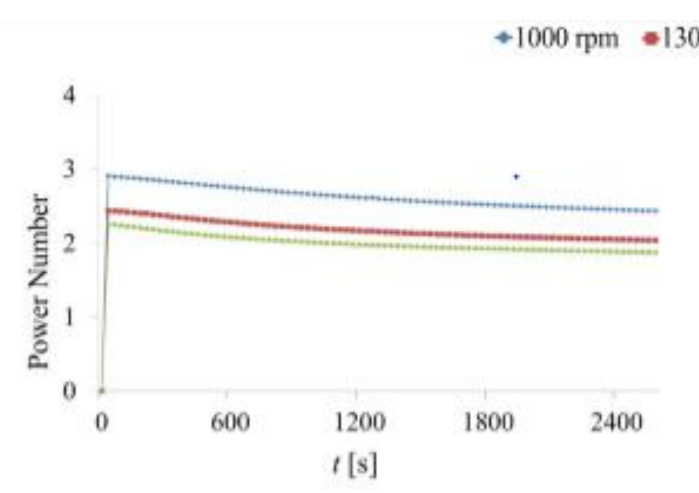

(a)

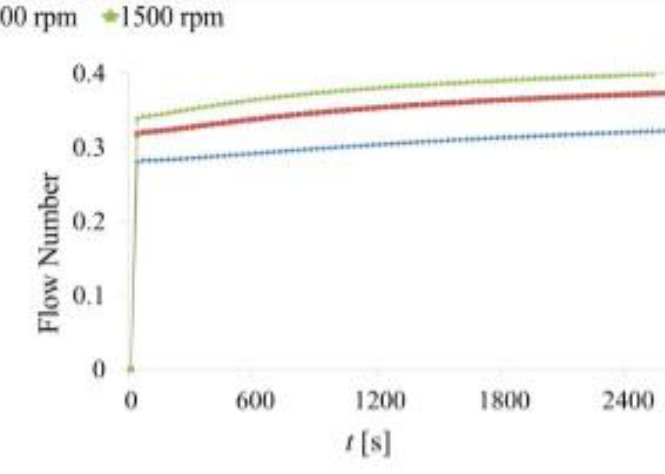

(b)

Figure 6 The predicted power numbers at various impeller rotational speeds (a) and the prediction flow number as a function of time (b)

The predicted power number for all rotational speeds falls slightly as the agitation time increases. This means there is a reduction in the power required to rotate the propeller in order to deliver dissipation energy to the fluid. This occurs as the viscosity around the propeller is decreased as a result of the molasses-water mixing mechanism. The graph also shows that the prediction power number decreases as the propeller rotational speed increases, thus revealing that the smaller the power number the more efficient the rate of stirring. The predicted flow numbers at each rotational speed are presented in Figure 6b, where it is shown that the flow number increases as 
the propeller rotational speed is raised. An increase in flow number indicates an increase in pumping capacity as the viscosity around the propeller is reduced. The mixing of molasses and water leads to decreased viscosity. Moreover, the graph shows that as the rotational speed of the propeller increases, so the value of the flow number increases in relation to the flow rate generated by the propeller, which is also significant.

\section{CONCLUSION}

The time-dependent flow field of two mutually dissolved liquids in a stirred vessel was predicted using ANSYS Fluent 18.2 version at three different propeller rotational speeds: 1000, 1300 and $1500 \mathrm{rpm}$. The RANS SKE was used as the turbulence model, and the MRF method was used for counting the moving-stationary frame interaction. The well-documented time-dependent flow fields of local velocity, flow pattern, molasses volume fraction value, density gradient, power number and flow number were elucidated. The flow pattern formed a non-symmetric double-loop circulation pattern near the propeller. The propeller vicinity velocity showed a maximum value of $3.83 \mathrm{~ms}^{-1}$. The predicted molasses volume fraction value, density gradient and power number all fell as a function of time at the different propeller rotational speeds under the mixing process, which was in contrast to the flow number, which was the opposite of the other variables. As the rotational speed increased, so the gradient further decreased. The profile of all the variables can be applied to determine the optimal operating conditions for mixing water and molasses with respect to the degree of mixing required.

\section{ACKNOWLEDGEMENT}

The United States Agency for International Development (USAID) supports the publication of this research/article through the Sustainable Higher Education Research Alliance (SHERA) Program for Universitas Indonesia's Scientific Modeling, Application, Research and Training for City-centered Innovation and Technology (SMART CITY) Project, Grant \#AID-497-A1600004, Sub Grant \#IIE-00000078-UI-1, contract number 0142/UN2.R3.SC/HKP.05.01/2018.

\section{REFERENCES}

Al-Qaessi, F., Abu-Farah, L., 2014. Prediction of Mixing Time for Miscible Liquids by CFD Simulation in Semi-batch and Batch Reactors. Engineering Applications of Computational Fluid Mechanics, Volume 3(1), pp. 135-146

Ansys-Fluent, 2017. Fluent 18.2 Documentation Fluent Theory Guide, Canonsburg. PA, USA, ANSYS, Inc.

Dakhel, A.A., Rahimi M., 2004. CFD Simulation of Homogenization in Large-scale Crude Oil Storage Tanks. Journal of Petroleum Science and Engineering, Volume 43(3-4), pp. 151161

Daryus, A., Siswantara, A.I., Darmawan, S., Gunadi, G.G.R., Camalia, R., 2016. CFD Simulation of Turbulent Flows in Proto X-3 Bioenergy Micro Gas Turbine Combustor using STD k- $\varepsilon$ and RNG k- $\varepsilon$ Model for Green Building Application. International Journal of Technology, Volume 7(2), pp. 204-211

Derksen, J.J., 2011. Blending of Miscible Liquids with Different Densities Starting from a Stratified State. Computers \& Fluids, Volume 50(1), pp. 35-45

Ge, C.Y., Wang, J.J., Gu, X.P., Feng L.F., 2014. CFD Simulation and PIV Measurement of the Flow Field Generated by Modified Pitched Blade Turbine Impellers. Chemical Engineering Research and Design, Volume 92(6), pp. 1027-1036

Launder, B.E., Spalding, D.B., 1974. The Numerical Computation of Turbulent Flows. Computer Methods in Applied Mechanics and Engineering, Volume 3(2), pp. 269-289 
Luo, J.Y., Issa, R.I., Gosman, A.D., 1994. Prediction of Impeller Induced Flows in Mixing Vessels using Multiple Frames of Reference. Institution of Chemical Engineers Symposium Series, Volume 136, pp. 549-556

Madhania, S., Cahyani, A.B., Nurtono, T., Muharam, Y., Winardi, S., Purwanto, W.W., 2018. CFD Study of Mixing Miscible Liquid with High Viscosity Difference in a Stirred Tank. In: IOP Conference Series: Materials Science and Engineering, Volume 316

Madhania, S., Nurtono, T., Cahyani, A.B., Carolina, Muharam, Y., Winardi, S., Purwanto, W.W., 2017. Mixing Behaviour of Miscible Liquid-liquid Multiphase Flow in Stirred Tank with Different Marine Propeller Installment by Computational Fluid Dynamics Method. Chemical Engineering Transactions, Volume 56, pp. 1057-1062

Marshall, E.M., Bakker, A., 2004. Computational Fluid Mixing. Handbook of Industrial Mixing, Paul, E.L., Atiemo-Obeng, V.A., Kresta, S.M., (eds.), John Wiley \& Sons, Inc., Hoboken, New Jersey, USA

Montante, G., Coroneo, M., Paglianti, A., 2016. Blending of Miscible Liquids with Different Densities and Viscosities in Static Mixers. Chemical Engineering Science, Volume 141, pp. 250-260

Muharam, Y., Kurniawan, A., 2016. Computational Fluid Dynamic Application in Scale-up of a Stirred-batch Reactor for Degumming Crude Palm Oil. International Journal of Technology, Volume 7(8), pp. 1344-1351

Orsi, G., Roudgar, M., Brunazzi, E., Galletti, C., Mauri, R., 2013. Water-Ethanol Mixing in Tshaped Microdevices. Chemical Engineering Science, Volume 95, pp. 174-183

Rahimi, M., 2005. The Effect of Impellers Layout on Mixing Time in a Large-scale Crude Oil Storage Tank. Journal of Petroleum Science and Engineering, Volume 46(3), pp. 161-170

Roache, P.J., 1994. A Method for Uniform Reporting of Grid Refinement Studies. J. Fluids Eng, Volume 116(3), pp. 405-413

Roache, P.J., 1997. Quantification of Uncertainty in Computational Fluid Dynamics. Annu. Rev. Fluid Mech., Volume 29(1), pp. 123-160

Patankar, S.V., 1980. Numerical Heat Transfer and Fluid Flow. Washington, DC: Hemisphere Publishing Corporation

Shih, T.H., Liou, W.W., Shabbir, A., Yang, Z., Zhu, J., 1995. A New k-€ Eddy Viscosity Model for High Reynolds Number Turbulent Flows. Computers \& Fluids, Volume 24(3), pp. 227 238

Singh, H., Fletcher D.F., Nijdam J.J., 2011. An Assessment of Different Turbulence Models for Predicting Flow in a Baffled Tank Stirred with a Rushton Turbine. Chemical Engineering Science, Volume 66(23), pp. 5976-5988

Sossa-Echeverria, J., Taghipour, F., 2015. Computational Simulation of Mixing Flow of Shear Thinning Non-Newtonian Fluids with Various Impellers in a Stirred Tank. Chemical Engineering and Processing: Process Intensification, Volume 93, pp. 66-78

Van Doormaal, J.P., Raithby, G.D., 1984. Enhancements of the Simple Method for Predicting Incompressible Fluid Flows. Numerical Heat Transfer, Volume 7(2), pp. 147-163

Wu, B., 2011. CFD Investigation of Turbulence Models for Mechanical Agitation of NonNewtonian Fluids in Anaerobic Digesters. Water Research, Volume 45(5), pp. 2082-2094

Yakhot, V., Orszag, S.A., 1986. Renormalization Group Analysis of Turbulence. I. Basic Theory. Journal of Scientific Computing, Volume 1(1), pp. 3-51

Zadghaffari, R., Moghaddas, J.S., Revstedt, J., 2009. A Mixing Study in a Double-Rushton Stirred Tank. Computers \& Chemical Engineering, Volume 33(7), pp. 1240-1246

Zhao, J., Gao, Z., Bao Y., 2011. Effects of the Blade Shape on the Trailing Vortices in Liquid Flow Generated by Disc Turbines. Chinese Journal of Chemical Engineering, Volume 19(2), pp. 232-242 